\title{
BMJ Open Prevalence of vestibular dysfunction and associated factors in South Korea
}

\author{
Ja-Won Koo, ${ }^{1}$ Mun Young Chang, ${ }^{1}$ Sook-young Woo, ${ }^{2}$ Seonwoo Kim, ${ }^{2}$ \\ Yang-Sun $\mathrm{Cho}^{3}$
}

To cite: Koo J-W, Chang MY, Woo S-young, et al. Prevalence of vestibular dysfunction and associated factors in South Korea. BMJ Open 2015;5:e008224. doi:10.1136/bmjopen-2015008224

- Prepublication history for this paper is available online. To view these files please visit the journal online (http://dx.doi.org/10.1136/ bmjopen-2015-008224).

Received 18 March 2015 Revised 11 August 2015 Accepted 18 September 2015

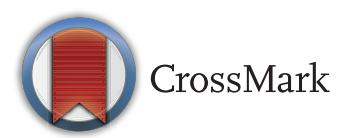

${ }^{1}$ Department of Otorhinolaryngology-Head and Neck Surgery, Seoul National University Bundang Hospital, Seoul National University College of Medicine, Seongnam, Republic of Korea

${ }^{2}$ Biostatistics Team, Samsung Biomedical Research Institute, Seoul, Republic of Korea

${ }^{3}$ Department of Otorhinolaryngology-Head and Neck Surgery, Samsung Medical Center, Sungkyunkwan University School of Medicine, Seoul, Republic of Korea

Correspondence to Professor Yang-Sun Cho; yscho@skku.edu

\section{ABSTRACT}

Objective: To report the nationwide prevalence of dizziness and vestibular dysfunction in the Korean population and determine the associated factors.

Design: Cross-sectional analysis of a nationwide health survey.

Methods: We obtained data from the 2009 to 2010 Korea National Health and Nutrition Examination Surveys, which were cross-sectional surveys of the South Korean civilian, non-institutionalised population aged 40 years and older ( $\mathrm{N}=3267)$. A field survey team performed interviews and physical examinations. Structured questionnaires were handed out and balance function tests using the modified Romberg test of standing balance on firm and compliant support surfaces were performed on participants. Failure on the modified Romberg test was regarded to indicate vestibular dysfunction.

Results: The prevalence of dizziness during the past year was $16.70 \%$ (95\% Cl $14.65 \%$ to $18.76 \%$ ). The presence of vestibular dysfunction was noted in $1.84 \%$ (95\% Cl $1.18 \%$ to $2.51 \%)$. In addition, the prevalence of experiencing falls and positional dizziness were $1.46 \%(95 \% \mathrm{Cl} 0.87 \%$ to $2.06 \%)$ and $1.73 \%(95 \% \mathrm{Cl}$ $1.17 \%$ to $2.29 \%$ ), respectively. Multivariable analysis revealed that dizziness was associated with increased age, female gender, hearing loss and stress. Vestibular dysfunction was associated with increased age, history of dizziness and hearing loss.

Conclusions: Vertigo and dizziness are the greatest contributors to the burden of disability in the aged population. Screening for dizziness and vestibular dysfunction, and management of associated factors might be important for improving compromised quality of life due to postural imbalance caused by vestibular problems.

\section{INTRODUCTION}

Dizziness and vertigo are frequent and disabling symptoms in primary care units but remain unexplained in $40-80 \%$ of patients. ${ }^{1-4}$ Dizziness and vertigo may have serious individual and social effects, causing interruption of daily activities in $40 \%$ of affected individuals. ${ }^{5}$ The significant effects of dizziness and vertigo have supported the need for an epidemiological investigation. ${ }^{3}$ 6-12 Understanding the prevalence of these conditions and identifying

\section{Strengths and limitations of this study}

- This is a nationwide health survey for the prevalence of dizziness and vestibular dysfunction, and associated factors.

- The prevalence of dizziness and vestibular dysfunction in Korea was $16.70 \%$ and $1.84 \%$, respectively.

- Dizziness was associated with increased age, female gender, hearing loss and stress. Vestibular dysfunction was associated with increased age, history of dizziness and hearing loss.

- As this is a cross-sectional analysis, only associated factors for dizziness and vestibular dysfunction were identified, and risk factors could not be investigated.

associated factors from a large-scale study would greatly contribute to patient care and relief of the social burden of dizziness and vertigo. The epidemiological survey of dizziness and vestibular dysfunction in the general population has rarely been carried out. The prevalence of dizziness for 1 year has been reported to range from $6.1 \%$ to $27 \% .^{910}$ The prevalence of vestibular dysfunction has also been reported with wide variability: $3.1-4.9 \%$ for 1 year prevalence, ${ }^{58}$ and $35.4 \%$ in a crosssectional study from the USA. ${ }^{6}$ This wide variability in population-based studies may be attributed to the different survey periods, diverse target populations and variable protocols.

The present study was undertaken to report the national prevalence of dizziness and vestibular dysfunction in South Korea, based on survey data obtained from the Korea National Health and Nutrition Examination Survey (KNHANES) 2009-2010, and to investigate the associated factors. Identification and modification of associated factors would help to reduce the incidence and/or severity of dizziness and, in turn, facilitate the efficient allocation of public health resources aimed at reducing the negative effects of dizziness in everyday life. 


\section{METHODS}

\section{Study population and data collection}

The KNHANES is an ongoing cross-sectional survey of the non-institutionalised population of South Korea. Every year, 10 000-12000 individuals in about 4600 households are selected from a panel to represent the population, using a multistage clustered and stratified random sampling method that is based on national census data. The participation rate of selected households in the past several cycles of KNHANES has been high, ranging from $79 \%$ to $84 \%$. Survey sample weights were used in all analyses to produce estimates that were representative of the non-institutionalised civilian Korean population.

A total of 3267 individuals, representative of the 10309130 individuals $\geq 40$ years of age in the country, participated in a survey of balance problems from 2009 to 2010. Among them, 1378 male participants represented 5040114 males and 1889 female participants represented 5269016 females.

Written informed consent was obtained from all the participants prior to the survey and approval for this research was given by the Institutional Review Board of the Samsung Medical Center (IRB number 2013-02-031).

\section{Balance survey and neurological examination}

Participants were asked whether they had experienced dizziness or imbalance ('Have you had dizziness or imbalance?'), positional dizziness ('Have you had severe vertigo when you rotate your head in supine position or when you sit up from bed or lie down in the morning?') and falls in the absence of external forces ('Have you ever fallen without any external factors?') in the past 12 months. To assess the balance function, we performed a modified Romberg test of standing balance on firm and compliant support surfaces. Participants were asked to stand on a firm surface with their feet $10 \mathrm{~cm}$ apart for at least $15 \mathrm{~s}$ in the same position as in the computerised dynamic posturography (CDP), with their arms crossed, without bending their knees or moving their bodies to maintain balance. They were not allowed to move their feet and had their eyes open (condition 1), then closed (condition 2). Next, we assessed the effect of eliminating somatosensory input on postural stability by repeating the same procedure but on an $18 \mathrm{~cm}$ thick, medium-density foam pad (polyurethane, $22 \mathrm{~kg} / \mathrm{m}^{3}$ ) with eyes open (condition 3), and then closed (condition 4), for at least 20s. The balance of each individual was scored on a pass/fail basis. Participants failed the balance test if they moved their feet, unfolded their hands, opened their eyes, or required the operator to intervene to maintain their balance. Romberg test on a foam pad with participants' eyes closed (condition 4) can provide information on the vestibular system's contribution to postural stability because motion related to visual input is eliminated and somatosensory inputs are masked in this condition.
Therefore, failure on the modified Romberg test from vestibular origin was defined as a state in which the participant passed test conditions 1-3 and did not pass test condition 4, and the participant was regarded as having vestibular dysfunction.

Participants were also asked whether they had experienced subjective hearing loss and tinnitus. The pure tone air-conduction threshold was measured in a soundproof booth using an automatic audiometer (GSI SA-203, Entomed Diagnostics AB, Lena Nodin, Sweden). Unilateral or bilateral hearing loss (HL) was defined as more than $25 \mathrm{~dB}$ HL in the average of air-conduction hearing thresholds at $0.5,1,2$ and $3 \mathrm{kHz}$ in one ear or both ears. ${ }^{13}$

\section{Analysis of associated factors}

Potential factors from the health examination and interview were evaluated for their association with the prevalence of dizziness and vestibular dysfunction in a total of 3267 participants aged 40 years or older (1378 males and 1889 females) surveyed from 2009 to 2010 . The evaluation included basic demographic factors, cardiovascular risk factors and other diseases that could cause falling. The factors that could be affected by dizziness or vestibular dysfunction were also evaluated (tables 1 and 2). Potential associated factors were evaluated using univariable analysis. Clinically important variables with a $\mathrm{p}$ value $<0.05$ were selected for multivariable analysis using a logistic regression model. Osteoporosis was evaluated in only those over 50 years of age and could not be included in the multivariable analysis. Variables with multicollinearity problems were not included in the logistic regression model.

\section{Statistical analysis}

The prevalence and 95\% CIs for dizziness and vestibular dysfunction were calculated. In the univariable and multivariable analysis, logistic regression analysis (using PROC SURVEYLOGISTIC in SAS) was used to test the association between dizziness/vestibular dysfunction and associated factors in a complex sampling design. $p$ Values and $95 \%$ CIs for OR were corrected using Bonferroni's method, due to multiple testing. If the OR is equal to 1 , there is no association between given variables of interest and dizziness/vestibular dysfunction. If the OR is higher than 1 (or lower than 1 ), the associated factor is positively (or negatively) related to dizziness/ vestibular dysfunction. To reflect national population estimates, sample weights were applied in all analyses. All $\mathrm{p}$ values were two sided, and $\mathrm{p}$ values $<0.05$ were considered to indicate statistical significance. Statistical analyses were performed using SAS V.9.3 (SAS Institute, Cary, North Carolina, USA).

\section{RESULTS}

The prevalence of dizziness and vestibular dysfunction Among the 3267 participants aged 40 years or older, 627 had experienced dizziness in the past 12 months; the 
Table 1 Analysis of factors associated with 'dizziness' in participants over 40 years of age $(\mathrm{N}=3267)$

\begin{tabular}{|c|c|c|c|c|c|c|c|c|c|}
\hline & \multirow[b]{2}{*}{ Per cent ${ }^{\star}$} & \multirow[b]{2}{*}{ Dizziness (+) } & \multirow[b]{2}{*}{ Dizziness (-) } & \multicolumn{3}{|c|}{ Univariable analysis } & \multicolumn{3}{|c|}{ Multivariable analysis $\dagger$} \\
\hline & & & & p Value & OR & $95 \% \mathrm{Cl}$ & p Value & OR & $95 \% \mathrm{Cl}$ \\
\hline \multicolumn{10}{|c|}{ Demographic characteristics } \\
\hline \multicolumn{10}{|c|}{ Age, years (mean) } \\
\hline $40-49(\%)$ & 42.48 & 13.19 & 86.81 & & Referer & & & Referent & \\
\hline $50-59(\%)$ & 29.00 & 12.87 & 87.13 & 1.00 & 0.97 & 0.65 to 1.46 & 1.00 & 0.97 & 0.63 to 1.49 \\
\hline 60-69 (\%) & 17.44 & 23.89 & 76.11 & $<0.001$ & 2.07 & 1.34 to 3.19 & 0.02 & 1.85 & 1.07 to 3.18 \\
\hline$\geq 70(\%)$ & 11.07 & 28.90 & 71.10 & $<0.001$ & 2.68 & 1.73 to 4.15 & 0.005 & 2.10 & 1.20 to 3.68 \\
\hline \multicolumn{10}{|l|}{ Gender } \\
\hline Male (\%) & 48.89 & 11.33 & 88.67 & & Referer & & & Referent & \\
\hline Female (\%) & 51.11 & 21.84 & 78.16 & $<0.001$ & 2.19 & 1.72 to 2.79 & $<0.001$ & 1.82 & 1.38 to 2.41 \\
\hline Body weight ( $n$ & & 60.28 & 63.80 & $<0.001$ & 0.97 & 0.96 to 0.98 & 0.09 & 0.99 & 0.97 to 1.00 \\
\hline BMI (mean)‡ & & 23.76 & 24.12 & 0.07 & 0.96 & 0.93 to 1.00 & & & \\
\hline WC (mean)‡ & & 81.62 & 82.98 & 0.02 & 0.98 & 0.97 to 1.00 & & & \\
\hline WC/height (me & & 0.51 & 0.51 & 0.51 & 2.08 & 0.23 to 18.60 & & & \\
\hline Annual househ & (mean)‡ & 4025.84 & 5072.45 & 0.22 & 0.98 & 0.95 to 1.01 & & & \\
\hline \multicolumn{10}{|c|}{ Level of education (college graduate or not) } \\
\hline No $(\%)$ & 77.62 & 17.94 & 82.06 & 0.007 & 0.65 & 0.47 to 0.89 & 0.91 & 0.98 & 0.69 to 1.39 \\
\hline \multicolumn{10}{|c|}{ Otolaryngological conditions (physical examination and questionnaire) } \\
\hline \multicolumn{10}{|c|}{ Tinnitus } \\
\hline Yes (\%) & 21.50 & 29.49 & 70.51 & $<0.001$ & 2.75 & 2.15 to 3.51 & & & \\
\hline \multicolumn{10}{|c|}{ Annoying tinnitus } \\
\hline No $(\%)$ & 65.80 & 30.61 & 69.39 & 0.50 & 0.85 & 0.54 to 1.35 & & & \\
\hline \multicolumn{10}{|c|}{ Subjective hearing loss } \\
\hline Yes (\%) & 2.31 & 39.39 & 60.61 & $<0.001$ & 3.37 & 1.95 to 5.84 & & & \\
\hline \multicolumn{10}{|c|}{ Unilateral hearing loss } \\
\hline Yes (\%) & 9.58 & 21.94 & 78.06 & 0.06 & 1.46 & 0.99 to 2.16 & & & \\
\hline \multicolumn{10}{|c|}{ Bilateral hearing loss } \\
\hline Yes (\%) & 5.85 & 30.14 & 69.86 & $<0.001$ & 2.29 & 1.54 to 3.40 & & & \\
\hline \multicolumn{10}{|c|}{ Unilateral or bilateral hearing loss } \\
\hline Yes $(\%)$ & 15.43 & 25.04 & 74.96 & $<0.001$ & 1.87 & 1.43 to 2.44 & 0.03 & 1.43 & 1.03 to 1.98 \\
\hline \multicolumn{10}{|c|}{ Data obtained from the questionnaire } \\
\hline \multicolumn{10}{|c|}{ Alcohol consumption (frequency, more than $2-4$ times/month) } \\
\hline No $(\%)$ & 40.86 & 18.76 & 81.24 & 0.06 & 0.78 & 0.60 to 1.01 & & & \\
\hline \multicolumn{10}{|c|}{ Alcohol consumption (frequency, more than 2 times/month) } \\
\hline No $(\%)$ & 61.66 & 16.85 & 83.15 & 0.84 & 0.97 & 0.75 to 1.26 & & & \\
\hline \multicolumn{10}{|c|}{ Alcohol consumption (frequency, more than 4 times/month) } \\
\hline Yes (\%) & 24.38 & 20.08 & 79.92 & 0.02 & 1.36 & 1.05 to 1.75 & 0.37 & 1.12 & 0.87 to 1.45 \\
\hline \multicolumn{10}{|c|}{ Smoking, current } \\
\hline No $(\%)$ & 77.60 & 17.97 & 82.03 & 0.01 & 0.64 & 0.46 to 0.91 & & & \\
\hline Smoking, past & & & & & & & & & \\
\hline No (\%) & 55.54 & 20.37 & 79.63 & $<0.001$ & 0.54 & 0.42 to 0.70 & & & \\
\hline History of angi & & & & & & & & & \\
\hline Yes (\%) & 2.34 & 20.13 & 79.87 & 0.46 & 1.27 & 0.67 to 2.37 & & & \\
\hline Diagnosis of a & oris & & & & & & & & \\
\hline Yes (\%) & 0.36 & 57.36 & 42.64 & 0.002 & 6.76 & 2.05 to 22.27 & 0.06 & 3.72 & 0.95 to 14.52 \\
\hline
\end{tabular}




\begin{tabular}{|c|c|c|c|c|c|c|c|c|c|}
\hline & \multirow[b]{2}{*}{ Per cent* } & \multirow[b]{2}{*}{ Dizziness (+) } & \multirow[b]{2}{*}{ Dizziness (-) } & \multicolumn{3}{|c|}{ Univariable analysis } & \multicolumn{3}{|c|}{ Multivariable analysis $†$} \\
\hline & & & & p Value & OR & $95 \% \mathrm{Cl}$ & p Value & OR & $95 \% \mathrm{Cl}$ \\
\hline \multicolumn{10}{|l|}{ Diagnosis of stroke } \\
\hline Yes $(\%)$ & 1.76 & 20.94 & 79.06 & 0.42 & 1.33 & 0.66 to 2.66 & & & \\
\hline \multicolumn{10}{|l|}{ Diagnosis of glaucoma } \\
\hline Yes $(\%)$ & 0.67 & 23.53 & 76.47 & 0.59 & 1.51 & 0.33 to 6.92 & & & \\
\hline \multicolumn{10}{|l|}{ Depressive mood } \\
\hline Yes $(\%)$ & 14.08 & 29.80 & 70.20 & $<0.001$ & 2.49 & 1.85 to 3.36 & & & \\
\hline \multicolumn{10}{|c|}{ Limitation of activity due to depressive mood or anxiety } \\
\hline Yes $(\%)$ & 0.83 & 56.74 & 43.26 & $<0.001$ & 6.70 & 3.30 to 13.63 & & & \\
\hline \multicolumn{10}{|l|}{ Diagnosis of depression } \\
\hline Yes $(\%)$ & 3.95 & 28.27 & 71.73 & 0.007 & 2.03 & 1.22 to 3.41 & & & \\
\hline \multicolumn{10}{|l|}{ Stress } \\
\hline Yes $(\%)$ & 24.18 & 24.49 & 75.51 & $<0.001$ & 1.96 & 1.52 to 2.52 & $<0.001$ & 1.99 & 1.53 to 2.58 \\
\hline$E Q-5 D$ index (mean) $\ddagger$ & & 0.89 & 0.95 & $<0.001$ & 0.01 & 0.01 to 0.04 & & & \\
\hline EuroQol (mean)‡ & & 66.06 & 76.09 & 0.09 & 0.99 & 0.97 to 1.00 & & & \\
\hline \multicolumn{10}{|l|}{ Laboratory data } \\
\hline \multicolumn{10}{|l|}{ Obesity } \\
\hline No (\%) & 64.55 & 17.72 & 82.28 & 0.08 & 0.81 & 0.64 to 1.03 & & & \\
\hline \multicolumn{10}{|l|}{ Hypertension } \\
\hline Yes (\%) & 33.70 & 19.81 & 80.19 & 0.01 & 1.39 & 1.08 to 1.78 & 0.81 & 1.03 & 0.78 to 1.36 \\
\hline \multicolumn{10}{|l|}{ Diabetes } \\
\hline Yes (\%) & 12.58 & 15.67 & 84.33 & 0.58 & 0.92 & 0.67 to 1.25 & & & \\
\hline \multicolumn{10}{|l|}{ Hypercholesterolaemia } \\
\hline Yes (\%) & 16.35 & 18.71 & 81.29 & 0.31 & 1.18 & 0.86 to 1.63 & & & \\
\hline \multicolumn{10}{|l|}{ Hypertriglycemia } \\
\hline No $(\%)$ & 81.03 & 17.52 & 82.48 & 0.04 & 0.72 & 0.52 to 0.98 & & & \\
\hline \multicolumn{10}{|l|}{ Dyslipidaemia } \\
\hline No $(\%)$ & 70.12 & 17.27 & 82.73 & 0.28 & 0.87 & 0.67 to 1.12 & & & \\
\hline \multicolumn{10}{|l|}{ Osteoporosis } \\
\hline Yes (\%) & 19.21 & 27.37 & 72.63 & $<0.001$ & 1.79 & 1.35 to 2.38 & & & \\
\hline \multicolumn{10}{|l|}{ Anaemia } \\
\hline Yes (\%) & 8.40 & 21.58 & 78.42 & 0.07 & 1.42 & 0.97 to 2.07 & & & \\
\hline \multicolumn{10}{|l|}{ Retinopathy } \\
\hline Yes (\%) & 21.55 & 18.33 & 81.67 & 0.30 & 1.16 & 0.88 to 1.52 & 0.15 & 0.78 & 0.56 to 1.09 \\
\hline \multicolumn{10}{|l|}{ Macular degeneration } \\
\hline Yes (\%) & 5.33 & 27.38 & 72.62 & 0.002 & 1.97 & 1.30 to 2.99 & 0.10 & 1.58 & 0.91 to 2.74 \\
\hline
\end{tabular}


Table 2 Analysis of factors potentially associated with 'vestibular dysfunction' in participants over 40 years of age $(\mathrm{N}=3267)$

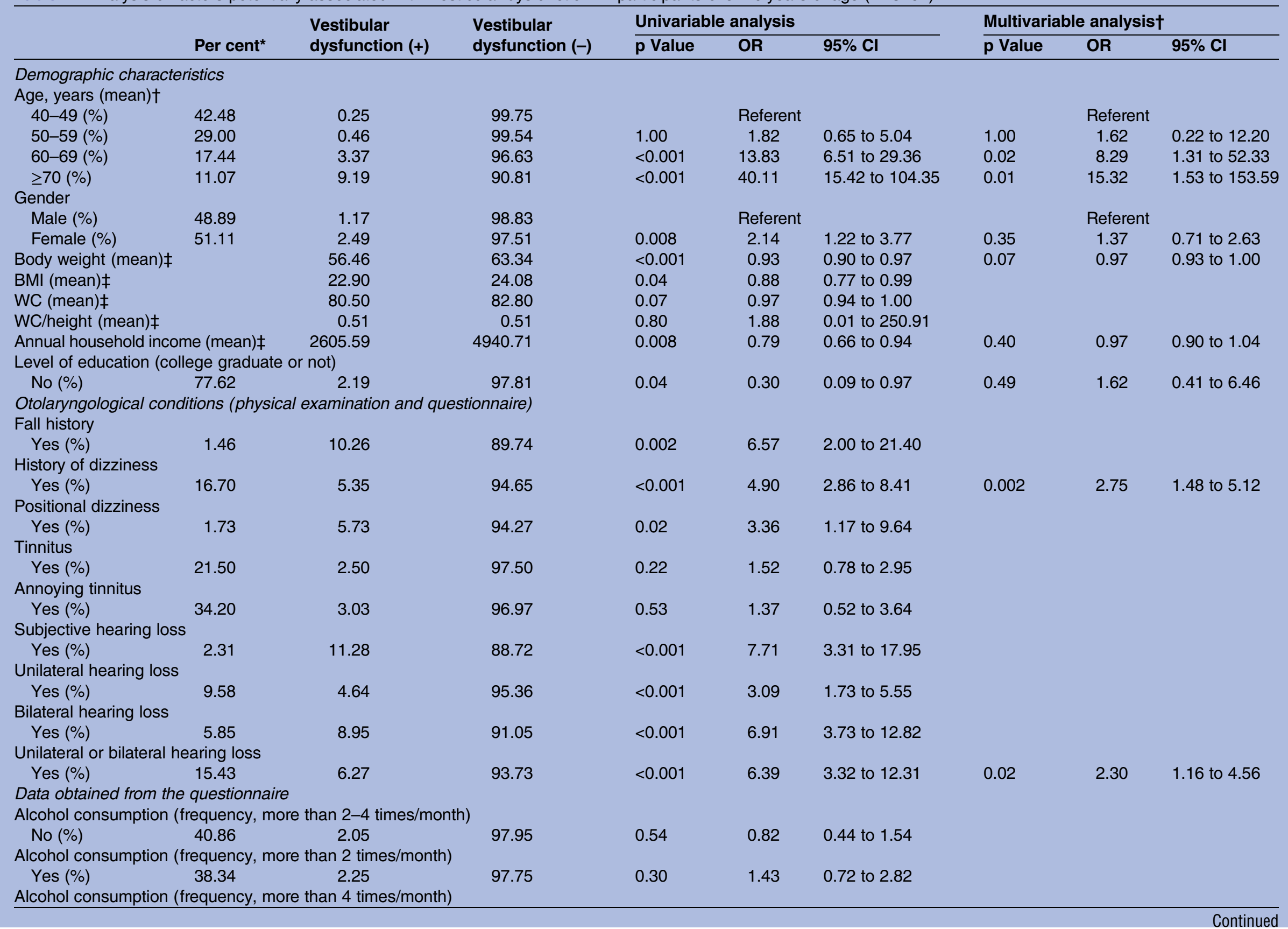




\begin{tabular}{|c|c|c|c|c|c|c|c|c|c|}
\hline & \multirow[b]{2}{*}{ Per cent ${ }^{\star}$} & \multirow{2}{*}{$\begin{array}{l}\text { Vestibular } \\
\text { dysfunction (+) }\end{array}$} & \multirow{2}{*}{$\begin{array}{l}\text { Vestibular } \\
\text { dysfunction (-) }\end{array}$} & \multicolumn{3}{|c|}{ Univariable analysis } & \multicolumn{3}{|c|}{ Multivariable analysis $\dagger$} \\
\hline & & & & p Value & OR & $95 \% \mathrm{Cl}$ & p Value & OR & $95 \% \mathrm{Cl}$ \\
\hline Yes (\%) & 24.38 & 2.97 & 97.03 & 0.06 & 2.04 & 0.97 to 4.26 & & & \\
\hline \multicolumn{10}{|c|}{ Alcohol consumption (volume, more than $5-6$ cups/event) } \\
\hline Yes (\%) & 55.64 & 1.88 & 98.12 & 0.88 & 1.05 & 0.56 to 1.99 & & & \\
\hline \multicolumn{10}{|c|}{ Alcohol consumption (volume, more than $7-9$ cups/event) } \\
\hline Yes (\%) & 44.83 & 2.24 & 97.76 & 0.22 & 1.48 & 0.79 to 2.78 & & & \\
\hline \multicolumn{10}{|c|}{ Alcohol consumption (volume, more than $10 \mathrm{cups} / \mathrm{event}$ ) } \\
\hline Yes (\%) & 36.41 & 2.49 & 97.51 & 0.10 & 1.71 & 0.90 to 3.25 & & & \\
\hline \multicolumn{10}{|l|}{ Smoking, current } \\
\hline \multirow{2}{*}{\multicolumn{10}{|c|}{ Smoking, past }} \\
\hline & & & & & & & & & \\
\hline No $(\%)$ & 55.54 & 2.21 & 97.79 & 0.15 & 0.62 & 0.32 to 1.19 & & & \\
\hline \multicolumn{10}{|c|}{ Diagnosis of angina pectoris } \\
\hline Yes (\%) & 2.34 & 3.61 & 96.39 & 0.26 & 2.04 & 0.29 to 7.07 & & & \\
\hline \multicolumn{10}{|c|}{ Limitation of activity due to heart problem } \\
\hline Yes (\%) & 0.36 & 2.82 & 97.18 & 0.68 & 1.55 & 0.19 to 12.44 & & & \\
\hline \multicolumn{10}{|l|}{ Diagnosis of stroke } \\
\hline \multirow{2}{*}{\multicolumn{10}{|c|}{ Diagnosis of glaucoma }} \\
\hline & & & & & & & & & \\
\hline Yes (\%) & 0.67 & 2.79 & 97.21 & 0.68 & 1.60 & 0.17 to 14.66 & & & \\
\hline \multicolumn{10}{|l|}{ Depressive mood } \\
\hline No (\%) & 85.92 & 1.96 & 98.04 & 0.20 & 0.59 & 0.26 to 1.32 & & & \\
\hline \multicolumn{10}{|c|}{ Limitation of activity due to depressive mood or anxiety } \\
\hline Yes (\%) & 0.83 & 3.27 & 96.73 & 0.10 & 1.81 & 0.89 to 3.72 & & & \\
\hline \multicolumn{10}{|c|}{ Diagnosis of depression } \\
\hline \multirow{2}{*}{\multicolumn{10}{|c|}{ Stress }} \\
\hline & & & & & & & & & \\
\hline No (\%) & 75.82 & 1.90 & 98.10 & 0.67 & 0.87 & 0.46 to 1.63 & & & \\
\hline EQ-5Dindex (mean)‡ & & 0.82 & 0.94 & $<0.001$ & 0.01 & 0.00 to 0.04 & & & \\
\hline EuroQol (mean)‡ & & 68.55 & 74.52 & 0.09 & 0.99 & 0.97 to 1.00 & & & \\
\hline \multicolumn{10}{|l|}{ Laboratory data } \\
\hline \multicolumn{10}{|l|}{ Obesity } \\
\hline No $(\%)$ & 64.55 & 2.15 & 97.85 & 0.14 & 0.60 & 0.30 to 1.18 & & & \\
\hline \multicolumn{10}{|l|}{ Hypertension } \\
\hline Yes (\%) & 33.70 & 3.46 & 96.54 & $<0.001$ & 3.47 & 2.13 to 5.67 & 0.23 & 1.39 & 0.81 to 2.36 \\
\hline \multicolumn{10}{|l|}{ Diabetes } \\
\hline Yes (\%) & 12.58 & 3.78 & 96.22 & 0.006 & 2.47 & 1.29 to 4.73 & 0.20 & 1.59 & 0.79 to 3.21 \\
\hline \multicolumn{10}{|c|}{ Hypercholesterolaemia } \\
\hline No $(\%)$ & 83.65 & 1.87 & 98.13 & 0.79 & 0.90 & 0.42 to 1.94 & & & \\
\hline Hypertriglycemia & & & & & & & & & \\
\hline $\begin{array}{c}\text { Yes (\%) } \\
\text { Dyslipidaemia }\end{array}$ & 18.97 & 2.73 & 97.27 & 0.14 & 1.69 & 0.85 to 3.35 & & & \\
\hline
\end{tabular}

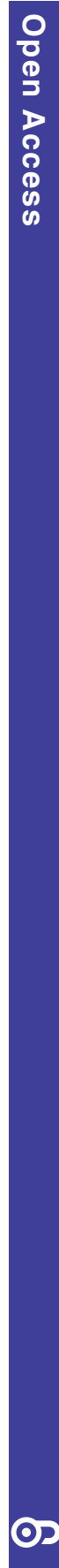




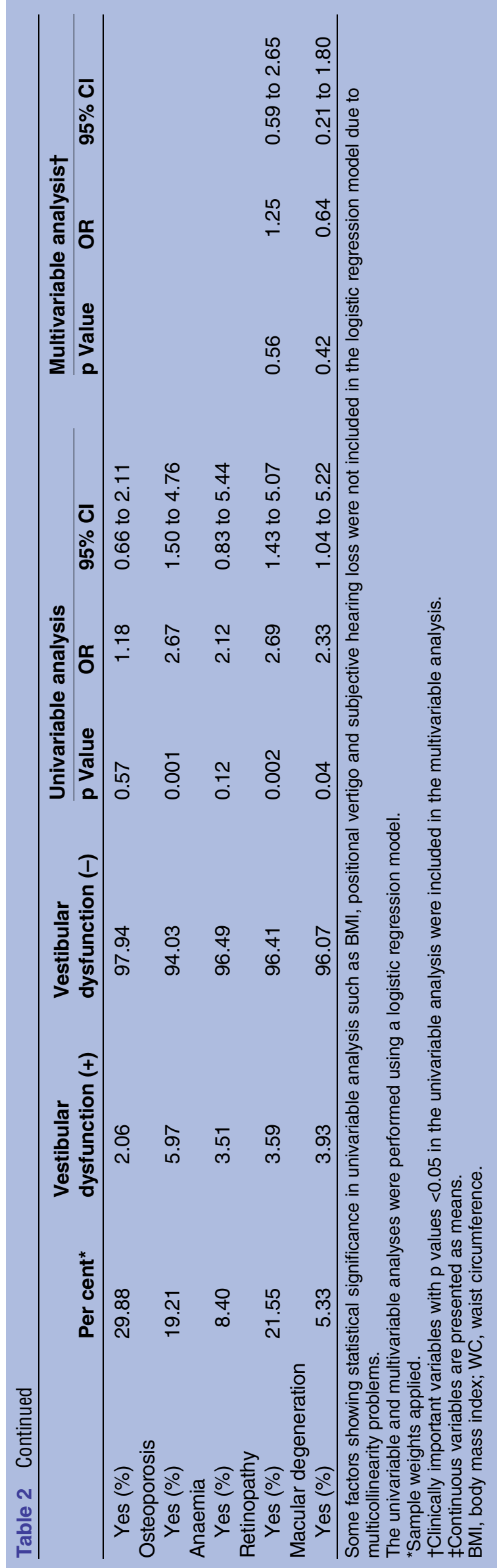

prevalence of dizziness was $16.70 \%$ (95\% CI $14.65 \%$ to $18.76 \%)$. The prevalence of experiencing falls and positional dizziness was $1.46 \%$ (95\% CI $0.87 \%$ to $2.06 \%$ ) and $1.73 \%$ (95\% CI $1.17 \%$ to $2.29 \%$ ), respectively. Seventy-five participants showed vestibular dysfunction, representing a prevalence of $1.84 \%(95 \%$ CI $1.18 \%$ to $2.51 \%$ ).

\section{Analysis of associated factors}

In the univariable analysis, dizziness was associated with several factors (table 1). Among the variables significantly associated with dizziness, age, gender, body weight, level of education, objective hearing loss (unilateral or bilateral), alcohol consumption, angina pectoris, emotional stress, hypertension, retinopathy and macular degeneration were selected for the multivariable analysis. We did not include variables with multicollinearity problems such as waist circumference, volume of alcohol consumption, depressive mood, limitation of activity due to depressive mood or anxiety, and a diagnosis of depression in the logistic regression model. Quality of life (QOL) was not included in multivariable analysis either, since QOL is known to be affected by dizziness. In the multivariable analysis, age $(\mathrm{p}=0.02$, OR 1.85 ; $95 \%$ CI 1.07 to 3.18 for $60-69 ; p=0.005$, OR $2.1 ; 95 \%$ CI 1.20 to 3.68 for $\geq 70)$, gender $(\mathrm{p}<0.001$, OR 1.82 ; $95 \%$ CI 1.38 to 2.41), objective hearing loss (unilateral or bilateral) ( $\mathrm{p}=0.03$, OR $1.43 ; 95 \%$ CI 1.03 to 1.98 ) and emotional stress $(p<0.001$, OR $1.99 ; 95 \%$ CI 1.53 to 2.59$)$, remained as independent factors associated with dizziness (table 1).

For vestibular dysfunction, several factors were associated with univariable analysis (table 2). Among the variables significantly associated with vestibular dysfunction, age, gender, body weight, annual household income, level of education, history of dizziness, objective hearing loss (unilateral or bilateral), hypertension, diabetes mellitus, retinopathy and macular degeneration were selected for the multivariable analysis. We did not include variables with multicollinearity problems such as body mass index, fall history, positional dizziness, subjective hearing loss, unilateral hearing loss and bilateral hearing loss in the logistic regression model. The multivariable analysis demonstrated that age $(\mathrm{p}=0.02$, OR 8.29; $95 \%$ CI 1.31 to 52.33 for $60-69$; $\mathrm{p}=0.01$, OR 15.32 ; $95 \%$ CI 1.53 to 153.59 for $\geq 70$ ), history of dizziness ( $p=0.002$, OR $2.75 ; 95 \%$ CI 1.48 to 5.12 ) and objective hearing loss (unilateral or bilateral) $(\mathrm{p}=0.02$, OR 2.30; $95 \%$ CI 1.16 to 4.56 ) were associated with vestibular dysfunction (table 2).

\section{DISCUSSION}

Reliable epidemiological information is a key factor for provision of appropriate healthcare, preventive screenings and rehabilitative services. This report is the first nationwide epidemiological study in South Korea to investigate the prevalence and factors associated with 


\begin{tabular}{|c|c|c|c|c|c|c|}
\hline Authors & Year & Sample & $\begin{array}{l}\text { Method of evaluating } \\
\text { dizziness }\end{array}$ & $\begin{array}{l}\text { Method of } \\
\text { evaluating } \\
\text { vestibular } \\
\text { dysfunction }\end{array}$ & $\begin{array}{l}\text { Prevalence of } \\
\text { dizziness } \\
\text { (prevalence period) }\end{array}$ & $\begin{array}{l}\text { Prevalence of vestibular } \\
\text { dysfunction (prevalence } \\
\text { period) }\end{array}$ \\
\hline Kroenke and Price ${ }^{3}$ & $1981-1984$ & $\begin{array}{l}\text { USA, } 13538 \text { persons } \\
18 \text { years of age or older }\end{array}$ & Interview survey & & 23.2\% (lifetime) & \\
\hline Nakashima et al ${ }^{10}$ & 1991 & $\begin{array}{l}\text { Japan, } 7685 \text { persons } \\
20 \text { years of age or older }\end{array}$ & $\begin{array}{l}\text { Postal } \\
\text { questionnaire-based } \\
\text { survey }\end{array}$ & & $\begin{array}{l}6.1 \% \text { (undefined } \\
\text { period) }\end{array}$ & \\
\hline Yardley et al ${ }^{12}$ & $\begin{array}{l}\text { Not } \\
\text { described }\end{array}$ & $\begin{array}{l}\text { UK, } 2064 \text { persons } \\
18-64 \text { years of age }\end{array}$ & $\begin{array}{l}\text { Postal } \\
\text { questionnaire-based } \\
\text { survey }\end{array}$ & & $23.3 \%$ (1 month) & \\
\hline Hannaford et al ${ }^{7}$ & 1998 & $\begin{array}{l}\text { Scotland, } 15788 \text { persons } \\
18 \text { years of age or older }\end{array}$ & $\begin{array}{l}\text { Postal } \\
\text { questionnaire-based } \\
\text { survey }\end{array}$ & & $\begin{array}{l}{ }^{*} 20.3 \% \\
\dagger 29.7 \% \\
\$ 11.3 \% \text { (lifetime) }\end{array}$ & \\
\hline Neuhauser et $a^{\Gamma}$ & 2003 & $\begin{array}{l}\text { Germany, } 4869 \text { persons } \\
18 \text { years of age or older }\end{array}$ & $\begin{array}{l}\text { Telephone interview } \\
\text { survey }\end{array}$ & $\begin{array}{l}\text { Telephone interview } \\
\text { survey }\end{array}$ & $22.9 \%$ (1 year) & $4.9 \%$ (1 year) \\
\hline Agrawal et a $\rho$ & 2001-2004 & $\begin{array}{l}\text { USA, } 5086 \text { persons } \\
40 \text { years of age or older }\end{array}$ & Interview survey & $\begin{array}{l}\text { Modified Romberg } \\
\text { test }\end{array}$ & & $\begin{array}{l}35.4 \% \text { (cross-sectional } \\
\text { survey) }\end{array}$ \\
\hline Lai et $a \beta$ & 2006 & $\begin{array}{l}\text { Taiwan, } 16838659 \text { persons } \\
18 \text { years of age or older }\end{array}$ & & $\begin{array}{l}\text { National health } \\
\text { insurance claims } \\
\text { database survey }\end{array}$ & & $3.1 \%$ ( 1 year) \\
\hline Mueller et $a{ }^{\rho}$ & 2008-2010 & $\begin{array}{l}\text { Germany, } 4080 \text { persons } \\
65 \text { years of age or older }\end{array}$ & $\begin{array}{l}\text { Telephone interview } \\
\text { survey }\end{array}$ & & $27.0 \%$ (1 year) & \\
\hline Mendel et $a f^{29}$ & $\begin{array}{l}\text { Not } \\
\text { described }\end{array}$ & $\begin{array}{l}\text { Sweden, } 2547 \text { persons } \\
18 \text { years of age or older }\end{array}$ & $\begin{array}{l}\text { Postal } \\
\text { questionnaire-based } \\
\text { survey }\end{array}$ & & $21.0 \%$ (1 year) & \\
\hline Present study & 2009-2010 & $\begin{array}{l}\text { South Korea, } 3267 \text { persons } \\
40 \text { years of age or older }\end{array}$ & Interview survey & $\begin{array}{l}\text { Modified Romberg } \\
\text { Test }\end{array}$ & $16.70 \%$ (1 year) & $\begin{array}{l}1.84 \% \text { (cross-sectional } \\
\text { survey) }\end{array}$ \\
\hline
\end{tabular}


dizziness and vestibular dysfunction based on representative data from a government-centred survey.

\section{Prevalence of dizziness and vestibular dysfunction}

Several population-based studies have attempted to estimate the prevalence of dizziness. Their results are described in table 3. As the methods of evaluating dizziness, age distribution and survey period of each study vary, substantial differences in prevalence of dizziness may exist, and, subsequently, direct comparisons among the studies are difficult. However, except for the result from the Japanese questionnaire-based survey (6.1\%), the prevalence of dizziness from the previous studies ranged from $15 \%$ to $30 \%$. Since appropriate evaluation of vestibular function is, practically, difficult in a mass study, fewer studies have investigated the prevalence of vestibular dysfunction, while more have examined the prevalence of subjective dizziness. The first method was a neurological interview for individual participants, which was performed by the German National Telephone Health Interview Survey (GNT-HIS). ${ }^{14}$ Although this method may have reached an appropriate category of dizziness by using structured history-taking, it could not collect the subjects' objective health information related to dizziness, such as blood pressure, complete blood count and balance function. The next method reviewed data from a national health insurance claims database, and was used in a Taiwanese study. ${ }^{8}$ Even though the diagnoses might have been precise, this method inevitably missed subjects who were not covered by insurance. The last method was the modified Romberg test on firm and compliant support surfaces, which was used in this study and in the National Health and Nutrition Examination Survey of the USA, 20012004 (NHANES). ${ }^{6}$ The modified Romberg test is a simple objective test that can be conducted without a trained examiner, the diagnostic value of which has been verified in several studies. Cohen et al reported that the modified Romberg test could distinguish between subjects with and without vestibular dysfunction. ${ }^{15}$ Agrawal et $a l^{16}$ also reported that individuals who failed the modified Romberg test condition 4 were at a high risk of falling. Recently, Hong et $a l^{17}$ reported that the sensitivity and specificity of this method for diagnosing vestibular dysfunction were $63 \%$ and $90 \%$, respectively, compared to condition 5 of the sensory organisation test in CDP. Therefore, vestibular dysfunction can be best evaluated using the modified Romberg test as a field evaluation tool in a large-scale survey.

The prevalence of vestibular dysfunction from these studies is described in table 3 . As the present study used data from a cross-sectional survey, it is reasonable that the prevalence of $1.84 \%$ in this report is slightly lower than that of the GNT-HIS (4.9\%) and of the Taiwanese study $(3.1 \%)$. On the other hand, it is more difficult to explain the large difference between the results of the present study and those from the US survey (35.4\%), which was also a cross-sectional survey. The difference may be attributable to the sensitivity of the test methods used for each study. Both studies adapted the modified Romberg test on firm and compliant support surfaces to evaluate vestibular dysfunction, but the test methods were slightly different. In the US NHANES, participants were asked to stand with their feet together with heels and great toes touching. However, in the present study, participants were asked to stand with their feet $10 \mathrm{~cm}$ apart, as described in the test protocol of Computerised Dynamic Posturography (CDP) in the vestibular laboratory. The results of four test conditions of the balance test using a foam pad correlated well with those of $\mathrm{CDP}^{17}$ Standing with feet apart also increased the test compliance of the participants and reflected more realistic balance function of daily living. Another difference was the thickness of the foam pad. The purpose of using a foam pad during the Romberg test is to mask somatosensory input during the test. Since a 3-inch-thick medium density foam pad was used in US NHANES, a commercially available medium density $\left(22 \mathrm{~kg} / \mathrm{m}^{3}\right) 6 \mathrm{~cm}$ thick foam pad was checked for its feasibility before launching of this survey. However, all the participants could easily feel the surface and proprioception was not masked enough. Therefore, we investigated the sensitivity, specificity and ORs of the modified Romberg test depending on the thickness of foam pad under different conditions $^{17}$ and, finally, we adopted an $18 \mathrm{~cm}$ thick, medium-density foam pad for field test to evaluate vestibular function. These disparities in sensitivity of test seem to be the main cause of the difference between the two surveys.

\section{Factors associated with dizziness and vestibular dysfunction}

Several studies have noted an association between age and dizziness. $^{6-8} 1214$ The US NHANES reported that age was significantly associated with vestibular dysfunction. ${ }^{6}$ GNT-HIS also reported that moderate-to-severe dizziness or vertigo increased with age and the prevalence reached $37 \%$ in the age group 60 years and older. ${ }^{14}$ Hannaford et $a l^{7}$ showed that problems of balance increased with age. Our study also showed that the prevalence of dizziness and vestibular dysfunction in the '60-69 years' and 'more than 70 years' age segments is significantly higher than for those in the '40-49 years' age segment. In multivariable analysis, dizziness and objective vestibular dysfunction assessed by the modified Romberg test showed a significant association with age (tables 1 and 2). The increase in prevalence with age can be explained by changes associated with the ageing of the vestibular system such as reduction of vestibular hair cells, degeneration of the cupula and otolith, and the ascending vestibular pathway. ${ }^{18-20}$

Female preponderance among individuals with dizziness has also been demonstrated in other studies. In a report from the UK, women were more likely to report dizziness than men $(\mathrm{OR}=1.66,95 \%$ CI 1.32 to 2.07$) .{ }^{12}$ GNT-HIS and the Taiwanese study also showed a female preponderance. ${ }^{8}{ }^{14}$ However, the presence of vestibular 
dysfunction was not different between male and female participants in the NHANES. ${ }^{6}$ In the multivariable analysis of our study, the female gender was associated with dizziness $(\mathrm{p}<0.001, \mathrm{OR}=1.82,95 \%$ CI 1.38 to 2.41$)$, while this association was not significant for vestibular dysfunction (tables 1 and 2).

It is not surprising that vestibular function is associated with hearing due to the anatomical proximity of the cochlea and vestibular organ, which also share a neural and vascular supply. GNT-HIS demonstrated that tinnitus had an independent effect on vestibular vertigo in multivariable analysis. ${ }^{14}$ NHANES showed that individuals with vestibular dysfunction were significantly more likely to have hearing loss. ${ }^{6}$ We also demonstrated an association between dizziness/vestibular dysfunction and hearing function. Objective hearing loss (unilateral or bilateral) remained an independent factor associated with both dizziness and vestibular dysfunction on multivariable analysis (tables 1 and 2).

Several studies have suggested variable association of cardiovascular risk factors with dizziness. GNT-HIS showed an association of vestibular vertigo with hypertension and hyperlipidaemia on multivariable analysis. However, diabetes, cardiovascular disease (angina pectoris, myocardial infarction or stroke), obesity and smoking had nonsignificant associations on multivariable analysis. ${ }^{14}$ Among the cardiovascular risk factors of the NHANES, diabetes, hypertension and smoking were significant on univariable analysis, but only diabetes showed a significant association with vestibular dysfunction on multivariable analysis. ${ }^{6}$ Although the issues of over-nutrition and morbid obesity associated with balance problems have been reported in the literature, ${ }^{21-23}$ a previous large-scale study did not demonstrate an association between obesity and problems of balance. ${ }^{11}$ In this study, none of the cardiovascular risk factors were associated with dizziness or vestibular dysfunction on multivariable analysis. Japanese studies have also shown that vertigo is not associated with metabolic syndrome, which is strongly related to cardiovascular disease. $^{2425}$

Several studies have reported evidence supporting an association between dizziness and psychological factors such as depression, anxiety and stress. GNT-HIS reported that depression was associated with vestibular vertigo. ${ }^{14}$ Likewise, another study reported that dizziness was associated with anxiety and depressive distress. ${ }^{26}$ In some reports, the prevalence of depression and anxiety approached $20 \%$ and $30 \%$, respectively, in vertiginous individuals. ${ }^{27}$ The present study also evaluated the associations of psychological factors. Although depression was not included in the multivariable analysis due to the multicollinearity problem, stress $(\mathrm{p}<0.001$, OR $1.99 ; 95 \%$ CI 1.53 to 2.58 ) showed a strong association with dizziness. While psychological well-being has shown significant association with dizziness in the aged population, vestibular dysfunction was not associated with psychological factors.

Lastly, the association between dizziness and vestibular dysfunction was analysed (table 2), and a history of dizziness remained as an independent factor for vestibular dysfunction in the multivariable analysis $(\mathrm{p}=0.0053$, OR 2.56; $95 \%$ CI 1.32 to 4.95$)$. These results confirm that vestibular dysfunction diagnosed by the modified Romberg test correctly reflects participants' vestibular vertigo.

Although this is a large-scale study based on representative data from a government-centred process, the crosssectional nature of the survey precluded the incidence estimates and risk factor analysis. Instead, we could obtain only prevalence rate and associated factors of dizziness and vestibular dysfunction, and this is a limitation of this study.

\section{Conclusions}

We demonstrated that the prevalence of dizziness during the past year and the prevalence of vestibular dysfunction were $16.70 \%$ and $1.84 \%$, respectively. The multivariable analysis revealed that dizziness was associated with increased age, female gender, hearing loss and emotional stress. Vestibular dysfunction was associated with increased age, history of dizziness and hearing loss. As it has been reported that vertigo and dizziness were the greatest contributors to the burden of disability in the aged population, ${ }^{9}$ screening for dizziness and vestibular dysfunction, and parallel interventions to modify the associated factors, are required in a rapidly ageing society.

Acknowledgements The authors gratefully acknowledge the 150 residents of the Departments of Otorhinolaryngology from 47 training hospitals in South Korea, members of the Committee for Epidemiologic Survey in the Korean Society of Otorhinolaryngology-Head and Neck Surgery, and members of the Division of Chronic Disease Surveillance in Korea Centers for Disease Control \& Prevention for participating in this survey, and the dedicated work they provided.

Contributors J-WK and Y-SC designed the study, wrote the first draft of the manuscript and took part in the data analyses. MYC wrote the first draft of the manuscript, took part in the interpretation of data and critically revised the manuscript for important intellectual content. S-yW and SK performed statistical analyses, commented on the text and helped in interpretation of the analyses. All the authors read and approved the submitted version of the manuscript.

Competing interests None declared.

Ethics approval Institutional Review Board of the Samsung Medical Center (IRB number 2013-02-031).

Provenance and peer review Not commissioned; externally peer reviewed.

Data sharing statement No additional data are available.

Open Access This is an Open Access article distributed in accordance with the Creative Commons Attribution Non Commercial (CC BY-NC 4.0) license, which permits others to distribute, remix, adapt, build upon this work noncommercially, and license their derivative works on different terms, provided the original work is properly cited and the use is non-commercial. See: http:// creativecommons.org/licenses/by-nc/4.0/

\section{REFERENCES}

1. Bird JC, Beynon GJ, Prevost AT, et al. An analysis of referral patterns for dizziness in the primary care setting. Br J Gen Pract 1998;48:1828-32. 
2. Kroenke K, Mangelsdorff AD. Common symptoms in ambulatory care: incidence, evaluation, therapy, and outcome. Am J Med 1989;86:262-6.

3. Kroenke K, Price RK. Symptoms in the community. Prevalence, classification, and psychiatric comorbidity. Arch Intern Med 1993;153:2474-80

4. Madlon-Kay DJ. Evaluation and outcome of the dizzy patient. J Fam Pract 1985;21:109-13.

5. Neuhauser HK, Radtke A, von Brevern M, et al. Burden of dizziness and vertigo in the community. Arch Intern Med 2008;168:2118-24.

6. Agrawal Y, Carey JP, Della Santina CC, et al. Disorders of balance and vestibular function in US adults: data from the National Health and Nutrition Examination Survey, 2001-2004. Arch Intern Med 2009;169:938-44.

7. Hannaford PC, Simpson JA, Bisset AF, et al. The prevalence of ear, nose and throat problems in the community: results from a national cross-sectional postal survey in Scotland. Fam Pract 2005;22:227-33.

8. Lai YT, Wang TC, Chuang LJ, et al. Epidemiology of vertigo: a National Survey. Otolaryngol Head Neck Surg 2011;145:110-16.

9. Mueller M, Strobl R, Jahn K, et al. Burden of disability attributable to vertigo and dizziness in the aged: results from the KORA-Age study. Eur J Public Health 2014;24:802-7.

10. Nakashima K, Yokoyama Y, Shimoyama R, et al. Prevalence of neurological disorders in a Japanese town. Neuroepidemiology 1996;15:208-13.

11. Neuhauser HK. Epidemiology of vertigo. Curr Opin Neurol 2007;20:40-6.

12. Yardley L, Owen N, Nazareth I, et al. Prevalence and presentation of dizziness in a general practice community sample of working age people. Br J Gen Pract 1998;48:1131-5

13. [No authors listed]. Committee on Hearing and Equilibrium guidelines for the evaluation of results of treatment of conductive hearing loss. American Academy of Otolaryngology-Head and Neck Surgery Foundation I. Otolaryngol Head Neck Surg 1995;113:186-7.

14. Neuhauser HK, von Brevern M, Radtke A, et al. Epidemiology of vestibular vertigo: a neurotologic survey of the general population. Neurology 2005;65:898-904.

15. Cohen H, Blatchly CA, Gombash LL. A study of the clinical test of sensory interaction and balance. Phys Ther 1993;73:346-51; discussion 51-4.
16. Agrawal $\mathrm{Y}$, Carey JP, Hoffman $\mathrm{HJ}$, et al. The modified Romberg Balance Test: normative data in U.S. adults. Otol Neurotol 2011;32:1309-11.

17. Hong SK, Park JH, Kwon SY, et al. Clinical efficacy of the Romberg test using a foam pad to identify balance problems: a comparative study with the sensory organization test. Eur Arch Otorhinolaryngol 2015;272:2741-7.

18. Igarashi M, Saito R, Mizukoshi K, et al. Otoconia in young and elderly persons: a temporal bone study. Acta Otolaryngol Suppl 1993;504:26-9.

19. Johnsson LG, Hawkins JE Jr. Sensory and neural degeneration with aging, as seen in microdissections of the human inner ear. Ann Otol Rhinol Laryngol 1972;81:179-93.

20. Konrad HR, Girardi M, Helfert R. Balance and aging. Laryngoscope 1999;109:1454-60.

21. Handrigan $\mathrm{G}$, Hue $\mathrm{O}$, Simoneau $\mathrm{M}$, et al. Weight loss and muscular strength affect static balance control. Int J Obes (Lond) 2010;34:936-42.

22. Hue O, Simoneau M, Marcotte J, et al. Body weight is a strong predictor of postural stability. Gait Posture 2007;26:32-8.

23. Teasdale $\mathrm{N}$, Hue $\mathrm{O}$, Marcotte $\mathrm{J}$, et al. Reducing weight increases postural stability in obese and morbid obese men. Int $J$ Obes (Lond) 2007;31:153-60.

24. Yamanaka T, Fukuda T, Sawai Y, et al. [Clinical analysis of metabolic syndrome in vertiginous diseases]. Nihon Jibiinkoka Gakkai Kaiho 2011;114:24-9.

25. Yamanaka T, Fukuda T, Shirota S, et al. The prevalence and characteristics of metabolic syndrome in patients with vertigo. PLoS ONE 2013;8:e80176.

26. Monzani D, Casolari L, Guidetti G, et al. Psychological distress and disability in patients with vertigo. J Psychosom Res 2001;50:319-23.

27. Grunfeld EA, Gresty MA, Bronstein AM, et al. Screening fo depression among neuro-otology patients with and without identifiable vestibular lesions: identificación de la depresión en pacientes neuro-otológicos con y sin lesiones vestibulares identificables. Int J Audiol 2003;42:161-5.

28. Ketola S, Havia M, Appelberg B, et al. Depressive symptoms underestimated in vertiginous patients. Otolaryngol Head Neck Surg 2007;137:312-15

29. Mendel B, Bergenius J, Langius-Eklöf A. Dizziness: a common, troublesome symptom but often treatable. J Vestib Res 2010;20:391-8. 